\title{
The resilience ability of vegetation after different fire recurrences in Provence
}

\author{
A. Schaffhauser ${ }^{1,2}$, T. Curt $^{2} \&$ T. Tatoni ${ }^{1}$ \\ ${ }^{1}$ Institut Méditerranéen d'Ecologie et de Paléoécologi \\ (UMR CNRS/IRD), Aix-Marseille Université, France \\ ${ }^{2}$ CEMAGREF, Aix-en-Provence, France
}

\begin{abstract}
Literature on relationships between wildfires and vegetation in Mediterranean areas indicates high resilience ability for most ecosystems on calcareous soils, but data are scarce for acidic soils. The resilience ability of a "fire-driven" ecosystem is expected to depend both on the characteristics of the ecosystem and on the fire recurrence.

We investigated the vegetation according to fire recurrence in a site with ecological and patrimonial stakes (the Maures massif, Provence, South Eastern France), in order to determine which ecosystems are more resilient and why. We sampled different modalities of fire recurrence (frequency of fires and interval of time between fires), and we investigated vegetation resilience to fire through different components such as composition, richness, diversity and structure. The sites corresponded to five modalities of increasing fire recurrence since 1959: control plots which had not burned since 1959, plots burned by a major and intense wildfire in 1990 (= reference fire), other plots burned twice or thrice before the 1990 fire and plots burned several times then and in 2003.

The results confirmed that our Mediterranean ecosystems on acidic soils are mainly auto-successional, as vegetation composition remained rather constant after fire. Significant differences of composition existed between the control plots and the plots lastly affected by the 2003 fire. In contrast, significant differences of functional diversity (i.e. plant traits) existed among the five modalities, in particular an increase of ruderal species and a decrease of competitive taxa with increasing fire recurrence. Moreover, some types of vegetation were identified according to fire recurrence modalities. A variation partitioning procedure (partial CCA) indicated that the environmental data set explained better the plant distribution than the fire recurrence data set.

The final objective of the study is to improve the understanding of the interrelationships between fires and the dynamics of vegetation, for a sustainable management of these Mediterranean ecosystems.
\end{abstract}

Keywords: fire recurrence, plant diversity, structure, auto-succession, acidic soils, common pool of species, shrublands, cork oak woodlands (Quercus suber L.). 


\section{Introduction}

The reaction of an ecosystem or a plant community to a disturbance can be measured in two ways: the resistance and the resilience. If the first concerns some species which can survive after the disturbance, the second integrates more processes so the community can return to the pre-disturbance state [1].

The fire, which is one of the most important disturbances under the Mediterranean climate, has various impacts on plants, since some species are destroyed or weakened by fire, while others, called pyrophytes [2], are favoured through the stimulation of their seed production or emergence (seeders), or their ability of resprouting (resprouters).

In "fire-prone" communities, the post-fire plant communities in particular were studied under the Mediterranean climate, on a time scale of a few years to about ten years $[3,4]$, the knowledge on a more important time scale and on siliceous substrate being scarcer.

In this context, most studies indicated high vegetation resilience for a few years after a fire (generally two or three years). The best strategies used by plants after a fire are resprouting and seeding. Besides, most Mediterranean tree species are resistant to fire, such as the cork oak (Quercus suber) [5].

In particular, the abundance of herbaceous species has been demonstrated [3, 4]. The same species recolonize the plots after a fire quite quickly. This is called "autosuccession" [4, 6, 7].

Few studies use a differentiation in sampling according to the fire recurrence $[6,8,9]$, owing to the difficulties to know accurately what has been the fire recurrence in a specific study area. Fire recurrence (sensu [10] has been defined as the nature, frequency (i.e. number of fires and interval of time between two fires), intensity, duration, season, and size of fires. It is hypothesized to affect plant community [1].

In southeastern France, the Var district is recurrently affected by wildfire. In particular, the Maures massif, which is developed on acidic soils, has been burned by large and intense wildfires along the past decades. Wildfires create gaps and affect the woodlands dominated by Quercus suber, which are legally protected owing to their ecological and patrimonial value. Fires are quite well known since 1959, allowing us to characterize the fire recurrence. In this paper, we aim to answer the following question: what are the effects of fire recurrence, in particular fire recurrence, on vegetation patterns, i.e. plant composition, richness, and diversity? Which factors of fire recurrence are the most important: effect of the last fire, number of fires, time interval between fires? Which part of fire and environment can we identify?

We would to test two hypotheses: (i) vegetation is resilient $[4,11,12]$ in terms of composition, diversity and whole structure for the plant communities on acidic soils after different fire recurrences, (ii) plant communities are autosuccessional [7], with a return to a quasi-initial state after disturbance.

For all these hypotheses, we focused on the expressed vegetation, excluding the seed bank. 


\section{Site and methods}

\subsection{Study area}

The study area is located in the "Maures" massif in southeastern France $\left(43^{\circ} 3 \mathrm{~N}\right.$; $6^{\circ} 3 \mathrm{E}$ ) which presents strong ecological and patrimonial stakes [13, 14]. It is made of acidic soils developed on granitic basement. This area has been affected by recurrent wildfires such as those of 1990 and 2003 that covered about 25,000 and 14,000 ha, respectively. All plots were located in the eastern part of the massif, on granitic and gneissic basement [15]. The main vegetation types are cork oak woodlands and shrublands called "maquis" with Erica arborea, Arbutus unedo and Cistus spp. These stands can be mixed.

\subsection{Sampling schedule}

We propose here to study the impacts of the recurrence of fires, using knowledge gathered over nearly fifty years by a diachronic analysis of images and aerial photographs, which has been carried out since 1959 .

The photointerpretation has been led in order to select some plots according to modalities of fire recurrence. Some aerial photographs (for the old fires) and satellites images (for the recent fires) were used to verify the presence of wildfires in these plots since 1959.

The sampling schedule has been based on fire recurrence: we have selected plots according to the number of fires experienced since 1959, and the time since the last fire (i.e. the date of the last fire). Two main reference wildfires have been selected because they were similar in terms of fire intensity and because they covered a wide area in the Maures massif: the 1990 wildfire which corresponds to an "old" fire allowing an almost complete reconstitution of the maquis vegetation [16], and the recent 2003 wildfire which offers a burned vegetation reference. Finally, the sampling was composed of the following modalities of fire recurrence. (i)The modality 1 (0Fire) includes control plots, which have not burned since 1959, (ii) the modality 2 (1Fire) concerns plots burned by a single fire in 1990, (iii) the modality 3 (Old fires) by several old fires (before 1964) before the fire of 1990, (iv) the modality 4 (Recent fires) by several recent fires (after 1970 and before 1985) before the fire of 1990, and, at last, (v) the modality 5 (New fire) by several fires before 1990 and 2003.

Thus, these five modalities are organized along an increasing gradient of fire recurrence (frequency of fires and interval of time between fires). We distinguish two extreme modalities $(1,5)$ that correspond to recently burned and unburned plots, and three intermediate modalities (2, 3 and 4) all burned in 1990 but with previous fires or not, the 1990 fire occurring early or late after the other fires.

These modalities should allow us to test the hypothesis of resilience on plant communities. The modality 1 will be compared with the other modalities of plots, burned at least once at several times by recurring fires. Moreover, modalities 3 and 4 were used to test the hypothesis of the time interval between fires (old fires in the 60's or recent fires in the 70's-80's, with 2-3 fires in total). 
All the plots had a medium fertility level, which corresponds to the most representative site type of the massif with soils of medium depth and position on medium slopes. We avoided the massif ridges and the steep valleys.

\subsection{Field survey}

At first, the stand structure was studied on 51 plots (10 repetitions per modality) in 2006. This first study was comprehensive: each tree or shrub was described (in space, with their dimensions) when the vegetation was not homogeneous. In the other case, the vegetation was described with some points of contact and a cover value on the plot.

Secondly, plant inventories were made with a methodology based on the works of [17]. We sampled the 51 plots in 2006 then 51 plots close to the first plots (same fire modality, same type of structure and ecological conditions) in 2007 for a total of 20 repetitions per modality. Plant inventories were made on each plot in spring, when a maximum of species can be identified. The area for each of them is $400 \mathrm{~m}^{2}$, compromise allowing to study both open and closed environments and which is the most used area in the ecology of plant communities $[18,19]$. For each sample, we studied some environmental factors (altitude, slope, exposure, abundance of nonvascular cryptogams, topsoil without vegetation cover, litter, stones...) and the visible vegetation according to five strata of vegetation, from the herbaceous species to high trees. For each strata, we determined the presence of the species and its abundance (according to the coefficient of abundance-dominance called here "CAD" adapted from [20]).

Nomenclature of species follows reference nomenclature of Kerguelen [21].

At last, for functional diversity, we have searched information on biological traits using the BASECO data base [22] and other data bases, directly accessible from literature or created from collected elements in literature [23-26].

In this paper, the main vital attributes are: biological types [Tybio] [27], linked to the persistence niche and known as good descriptors of functional groups in Provence, particularly for biology of conservation [28], vital types or adaptative strategies of Grime [Tyvit] for the competitive capacity [29], types of seeds' dispersal [Tyspread] for the dispersability [25, 30], post-fire regenerative types [Tyrej] revealing the propagule persistence capacity for fire disturbance, types of pollen's dispersal [Tyspoll], light tolerance types [Tylum], types of nutrition [Tynut] and phenology [Typhen].

\subsection{Data analyses}

All the measured variables are classified in two data sets: FIRE (variables of fire) and ENV (environmental factors). After some descriptive analyses, two types of analyses on vegetation and variables were operated: exploratory analyses (Correspondence Analysis) and ANOVA (variance analysis followed by test LSD, Confidence Interval 95\%) [31, 32] using the $\mathrm{R}$ statistical computing software (2.4.1., R Development Core Team, packages ade4 and vegan) and Statgraphics $^{\mathrm{TM}}$ software (Centurion XV, version 15.2.06, Statpoint, Inc.). 
The descriptive statistics consisted on calculating the specific richness, the specific diversity and equitability, and the Sorensen's index of similarity [33], then gathered by modality of fire recurrence.

The specific richness is the number of species per plot. The diversity index which has been calculated is the Shannon's index [34, 35] (2.4.1., $\mathrm{R}$ Development Core Team, package vegan):

$H^{\prime}=-\sum p i \log _{n} p i$, with pi the relative abundance of the taxon $\mathrm{i}$ in the sample $=$ CAD (species, total of all strata).

The equitability index is: $E=\frac{H^{\prime}}{\log _{n} N}$, with $\mathrm{N}$ the number of the species in the sample.

At last, the Sorensen's index is: $S=\frac{2 a}{(2 a+b+c)}$, with a=number of times where the species is present in the two tested modalities, $b=$ number of times where the species is absent in the first modality and present in the second, $\mathrm{c}=$ number of times where it's the opposite case.

ANOVA (ANalysis Of VAriance; one-way analysis of variance, followed by test LSD for determining the clusters) were used to compare vegetation variables according to the five modalities (e.g. richness, diversity and the proportion of vital attributes).

We realised the CA (Correspondence Analysis, [36]) to ordinate species or vital attributes of these species and plots on $\mathrm{R}$ software (R Development Core Team, package ade4). Finally, partial Canonical Correspondence Analysis (CCA is also called "direct gradient analysis") was used to account for shared variation between the two different sets of explanatory variables [37]. In order to evaluate the respective contribution of these sets of variables to species richness, multiple regression with a forward selection procedure of significant $(\mathrm{p}<0.005)$ variables was performed. This analysis was realised on $\mathrm{R}$ software (Ter Braak 2.4.1., $\mathrm{R}$ Development Core Team, vegan), with a selection of the more explicative variables by AIC step (Akaike information criterion, R Development Core Team, MASS) [38].

\section{Results}

\subsection{At the specific level}

Diversity and richness are significantly different between modalities $(p<0.05)$, with maximal values for the control plots (1) and minimal values for the plots burned in 2003 (5) (Figure 1). The intermediate modalities ( 3 and 4) have a mean level of richness and diversity.

The analysis of the ordination of the species and plots by CA (Figure 2) reveals little variability, as revealed by the weak distinction of clusters and the weak inertia. This is confirmed by the calculation of the index of similarity for the species of the five modalities where the values remain rather close. 


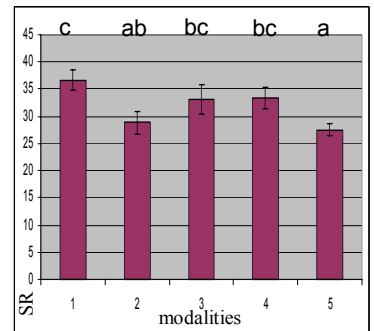

Specific richness*

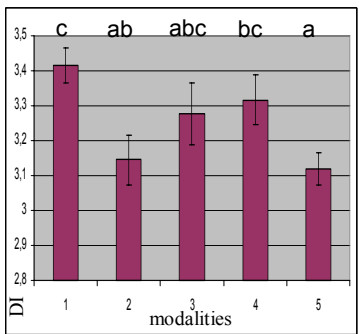

Diversity index *

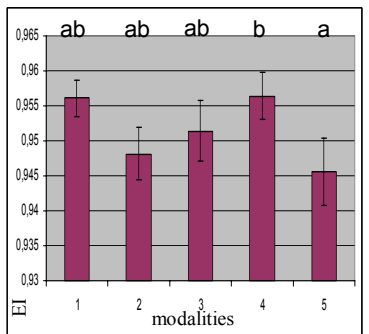

Equitability index

Figure 1: $\quad$ Specific richness, indexes of diversity and equitability according to an increasing gradient of fire recurrence (ANOVA and test LSD for the significance of the differences between the 5 modalities, CI 95\%). Data include 102 plots and 303 taxa. Fire recurrence modalities: (1) no fire, (2) 1990 fire, (3) old fires+1990, (4) recent fires +1990 and (5) recent fires $+1990+2003$.

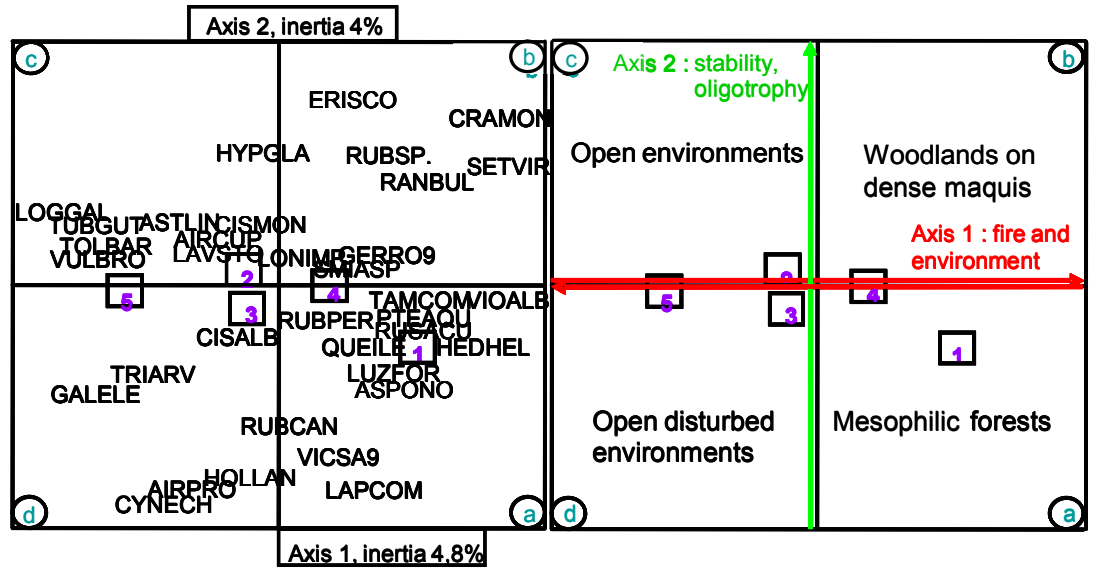

Figure 2: Factorial plans $1 / 2$ of the CA. Species observed only once were not considered in the analysis/102 plots, 191 species (here only the most contributive species were represented; the plots are illustrated by the barycentre of the modalities; i.e. 1 localizes the barycentre of the modality). Codes of the species are given in the Appendix.

The localization of the barycentres of the modalities shows a gradient opposing the most contrasted modalities ( 1 and 5 ). The other modalities are quite similar.

The factorial plan $1 / 2$ individualizes four groups:

- square (a): species of mesophilic forest environments (old and non disturbed forests, presence of Quercus pubescens),

- square (b): species of cork-oak woodlands on dense maquis (closed environments),

- square (c): species of opened maquis, croplands, 
- square (d); species of open environments disturbed (by fire, even very locally clearing and/or pasture).

The analyses showed that there is a "Common Pool of Species" (so called CPS), which corresponds to species present in more than one third of the samples. These species correspond to mosaic of maquis. They show the following characteristics:

- Sclerophyllous species of thickets (Quercus ilex, Arbutus unedo, Smilax aspera, Rubia peregrina, Asparagus acutifolius, Erica arborea),

- Heliophile and pyrophile species of the low maquis (Cistus monspeliensis, Calicotome spinosa, Cistus albidus, Cistus salviifolius, Lavandula stoechas),

- Predominantly ruderal species (Bituminaria bituminosa, Andryala integrifolia, Vicia disperma, Urospermum dalechampii, Carduus nigrescens, Euphorbia segetalis),

- Semi-forest herbaceous species, more shade-tolerant (Hieracium murorum, Geranium robertianum ssp purpureum),

- Quercus pubescens: main forest species, particularly in Northern slopes [39]

- Quercus suber: permanent species in our samples, its abundance is particularly linked with the ancient culture of cork, clearing and fire but is confirmed indigenous on the study area [39].

\subsection{At the functional level}

Functional diversity (Figure 3) doesn't follow the same patterns as the specific diversity. Some vital attributes have a maximum for the modality 1 (reference plots), as specific diversity. The types of seeds' dispersal and vital types have maximum values for the modality 4 . The maximum values generally correspond to 1 and 4, whereas they are minimal for the modalities 2 and 5, except for the regenerative types for which the $5^{\text {th }}$ presents a maximum value.

Several ANOVA were realised on PFTs. The figure 4 shows the evolution of the main Grime's strategies.

The SC and CS decrease with fire recurrence, having a maximum value for the modality 1, whereas RS and SR increase with fire recurrence, having a maximum value for the modality 5 .

Other analyses showed, according to fire recurrence:

- a decrease of the phanerophytes and an increase of the therophytes

- a slight increase for the anemochore taxa, with a maximum for the $5^{\text {th }}$ modality, whereas the zoochores taxa decrease, with a minimum for the modality 5

- the species able to resprout decrease, whereas the seeders (particularly the Cistus species) increase.

\subsection{Vegetation structure analysis}

The analyses on the whole structure show several types of vegetation (Figure 5) which globally follow a gradient of fire recurrence, except for the medium and 


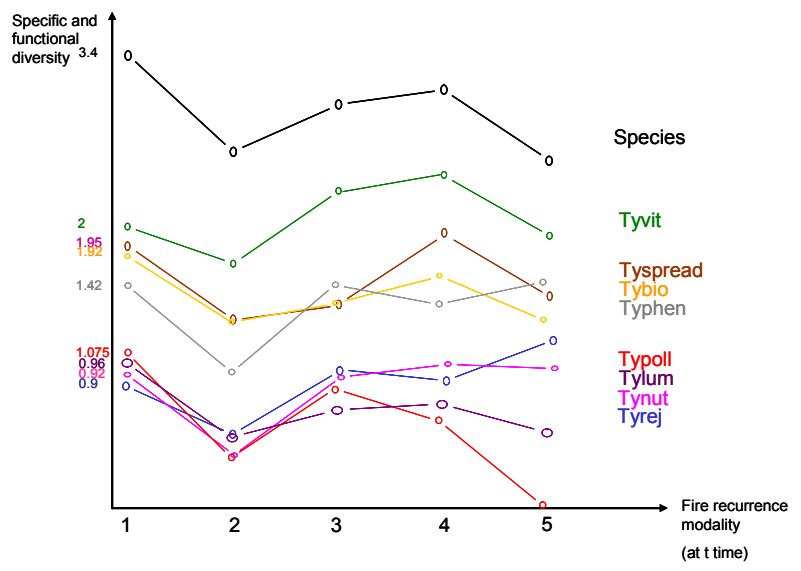

Figure 3: Comparison between functional and specific diversity (Shannon's indices). Tyvit: Grime's strategies, Tyspread: seeds' dispersal types, Tybio: Raunkiaer's types, Typhen: types of phenology, Typoll: types of pollens' dispersal, Tylum: types of light affinity, Tynut: types of nutrition, Tyrej: types or post-fire regeneration.

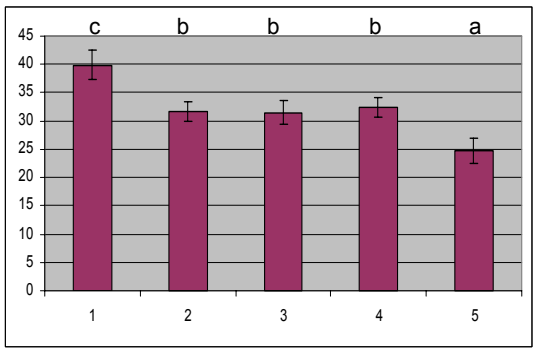

$[\mathrm{SC}]^{* * * *}$

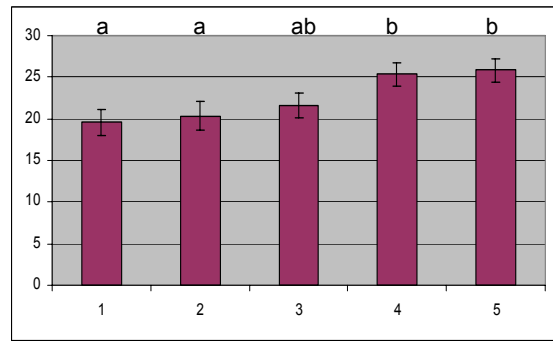

$[\mathrm{RS}]^{\text {** }}$

Figure 4: Variations of the [SC] (stress tolerant and competitive) and [RS] (stress tolerant and ruderal) taxa, $* * *<0,001 ; * *<0,01$. Letters indicate the clusters of LSD, $\mathrm{CI}=95 \%$.

high maquis distinct in terms of biomass but which can correspond with different fire intervals. Biomass increases from the low maquis to high maquis and shrublands where we observe a threshold of biomass quantity. Then biomass decreases when the shrubs in the sublayer become senescent and die.

\subsection{The part of fire and environment in plant distribution}

In the variance of plant composition, seven variables were explicative: orientation, altitude, slope, cover of cryptogams, airy litter, time after the last fire and number of fires. 


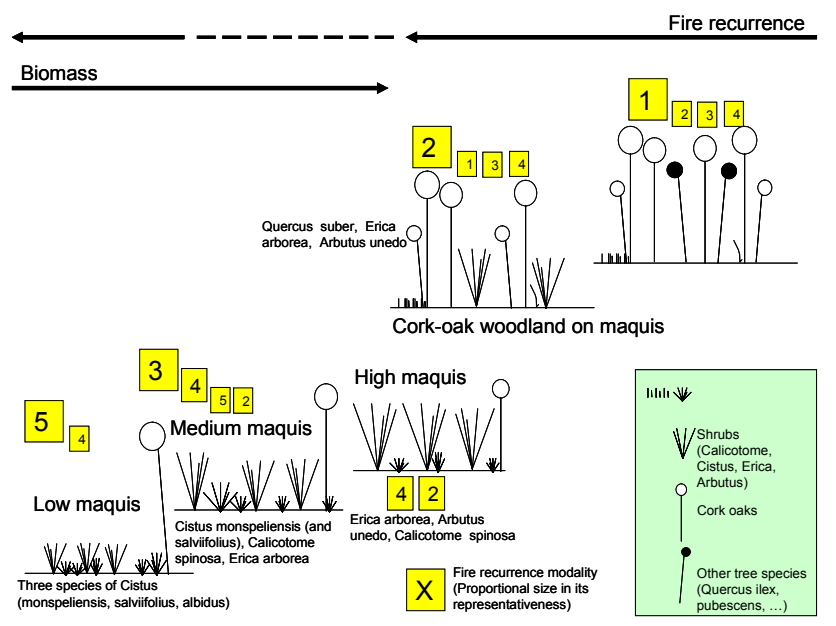

Figure 5: $\quad$ Scheme of the main types of vegetation on the study area.

With these variables, we obtain the following partitioning of variance: $10,77 \%$ for the global environment, $4,97 \%$ for the global fire, $9,43 \%$ for the environment only, 3,63\% for the fire only, 1,34\% for the common part where fire and environment both influence the species, giving a total explanation of $14,40 \%$ $(85,60 \%$ not explained).

Therefore, and despite the low explanation, the results show that the environmental factors explain more the variation of plant composition than the fire factors.

\section{Discussion}

We can divide the effects of fire recurrence on plants at the specific and functional levels according to:

- the effect of the time since the last fire: the modality 5 is significantly different from the modality 1 , which concerns plots not burned since 1959 (at least)

- the effect of the number of fires: leads to plots with lower diversity in the last modality for the species and some vital attributes, but with a relatively good resilience for the intermediate modalities

- the effect of the time interval between two successive fires: doesn't affect plant composition significantly for the modalities 3 and 4, but we observe some variations in PFTs' patterns.

Eventually, the last fire has the greatest effect and then both number of fires and time interval between two successive fires.

As the diversity of the modality 5 is lower than the others, this shows us (i) that our observations must have been realised just after the flush of herbaceous species known in short-time scale post-fire succession $[3,4]$ and (ii) that there is a decrease of resilience. 
The communities having a lower resilience are usually linked to strongly disturbed ecosystems or environments with a strong particularism [40, 41, 3].

Surprisingly, the modalities $1 ; 4$ and 2;5 are close for the ordination of species and for functional diversity. We hypothesized that these results come from different processes: for example, successively for the modalities 2 and 5, some phases of blocage and a decrease of resilience. Nevertheless, the similarity of 2;5 doesn't appear through the vegetation structure analysis, showing different types of vegetation.

Because of a strong floristic similarity, a Common Pool of Species was identified. Few floristic differences were also observed in a recent study in calcareous Provence [42].

The variations of PFTs according to fire recurrence show that functional diversity doesn't follow the same patterns as the specific diversity, like for other studies [43].

The analysis of variation partitioning procedure shows that the environmental variables have more influence than fire variables on plant species. This is linked with the history of fire in the Mediterranean type ecosystems, at least since the Neolithic in Southeastern France [39] and goes in the direction of the concept of endogeneous disturbance sensu (Rykiel [44]).

In fact, if the disturbance becomes an integrant part of the system, particularly for environments regularly affected by grazing [45], the disturbance can also be defined as a stress [46, 47].

\section{Conclusion and prospects}

Our results support the hypothesis of post-fire resilience of the studied ecosystems and of auto-succession, which is observed in the majority of the studies on post-fire plant communities $[8,1,3]$, even if some of them can show a lower resilience with the fire recurrence or a strong particularism $[40,41,3]$. That was the case through some of our results, with a lower specific richness for the modality of the stronger recurrence of fire but not exactly the same case for vital attributes, which don't vary with the same patterns.

The existence of a Common Pool of Species is in particular linked with the history of the Mediterranean ecosystems moulded by fire since at least the Neolithic and goes in the direction of the concept of endogeneous disturbance sensu Rykiel.

If the effects of fire recurrence on vegetation are weak at the specific level, they are clearer on the Plant Functional Traits, as it is also the case for other disturbances such which grazing or clearing [47] and the whole structure of vegetation which shows more variations of resilience.

The final objective of the study is to improve the understanding of the interrelationships between fires and the dynamics of vegetation, and to implement fire behaviour models for a sustainable management of these Mediterranean ecosystems. 


\section{Appendix}

\begin{tabular}{|c|c|c|}
\hline IDE: genus species ssp & IDE: genus species ssp & IDE: genus species ssp \\
\hline AIRCUP: Aira cupaniana & HOLLAN: Holcus lanatus & $\begin{array}{ll}\text { RUSACU: } & \text { Ruscus } \\
\text { aculeatus }\end{array}$ \\
\hline AIRPRO: Aira provincialis & $\begin{array}{l}\text { HYPGLA: } \\
\text { glabra }\end{array}$ & RUBSP. : Rubus sp. \\
\hline $\begin{array}{l}\text { ASPONO: } \\
\text { onopteris }\end{array}$ & $\begin{array}{l}\text { LAPCOM: } \\
\text { communis }\end{array}$ & SETVIR: Setaria viridis \\
\hline $\begin{array}{l}\text { ASTLIN: Asterolinon } \\
\text { linum-stellatum }\end{array}$ & $\begin{array}{l}\text { LAVSTO: } \\
\text { stoechas }\end{array}$ & SMIASP: Smilax aspera \\
\hline CISALB: Cistus albidus & LOGGAL: Logfia gallica & $\begin{array}{l}\text { TAMCOM: } \\
\text { communis }\end{array}$ \\
\hline $\begin{array}{l}\text { CISMON: } \\
\text { monspeliensis }\end{array}$ & LONIMP: Lonicera implexa & TOLBAR: Tolpis barbata \\
\hline $\begin{array}{l}\text { CRAMON: } \\
\text { monogyna }\end{array}$ & LUZFOR: Luzula forsteri & $\begin{array}{l}\text { TRIARV: } \\
\text { arvense }\end{array}$ \\
\hline $\begin{array}{l}\text { CYNECH: } \\
\text { echinatus }\end{array}$ & $\begin{array}{l}\text { PTEAQU: } \\
\text { aquilinum }\end{array}$ & $\begin{array}{l}\text { TUBGUT: } \\
\text { guttata }\end{array}$ \\
\hline ERISCO: Erica scoparia & QUEILE: Quercus ilex s.l. & $\begin{array}{l}\text { VICSA9: } \\
\text { nigra }\end{array}$ \\
\hline $\begin{array}{l}\text { GALELE: } \\
\text { elegans }\end{array}$ & $\begin{array}{l}\text { RANBUL: } \\
\text { bulbosus }\end{array}$ & VIOALB: Viola alba \\
\hline $\begin{array}{l}\text { GERRO9: } \\
\text { robertianum purpureumium }\end{array}$ & RUBCAN: Rubus canescens & $\begin{array}{l}\text { VULBRO: } \\
\text { bromoides }\end{array}$ \\
\hline $\begin{array}{l}\text { HEDHEL: Hedera helix } \\
\text { s.l. }\end{array}$ & $\begin{array}{l}\text { RUBPER: Rubia pe } \\
\text { s.l. }\end{array}$ & \\
\hline
\end{tabular}

\section{References}

[1] Trabaud, L., Evolution après incendie de la structure de quelques phytocénoses méditerranéennes du Bas-Languedoc (Sud de la France). Ann. Sci. Forest. 40 (2): pp. 177-196, 1983.

[2] Kunholtz-Lordat, G., La terre incendiée. Nîmes: Maison Carrée. 361pp., 1938.

[3] Bonnet, V., T. Dutoit, and T. Tatoni, Spatial gradients of vegetation and soil after fire in the calcareous Provence (France), in Fire and Biological Processes. Trabaud, L. \& Prodon, R. Backhuys publishers. pp. 303-314, 2002.

[4] Trabaud, L. and J. Lepart, Diversity and stability in garrigue ecosystems after fire. Vegetatio. 43 (1/2): pp. 49-57, 1980.

[5] Silva, J.S. and F. Catry, Forest fires in cork oak (Quercus Suber L.) stands in Portugal. International Journal of Environmental Studies. 63,3: pp. 235257(23), 2006.

[6] Delitti, W., et al., Effects of fire recurrence in Quercus coccifera L. shrublands of the Valencia Region (Spain): I. plant composition and productivity. Plant Ecology. 177(1): pp. 57-70, 2005.

[7] Egler, F.E., Vegetation science concepts I initial floristic composition, a factor in old-field vegetation development. Vegetatio. 4: pp. 412-417, 1954. 
[8] Buhk, C., et al., Post-fire regeneration in a Mediterranean pine forest with historically low fire frequency. Acta Oecologica. 30(3): pp. 288-298, 2006.

[9] Lloret, F., Vila, M, Diversity patterns of plant functional types in relation to fire regime and previous land use in Mediterranean woodlands. J. Veg. Sci. 14(3): pp. 387-398, 2003.

[10] Gill, A.M., Fire and the Australian landscape. Landscape Planning. 6: pp. 343-357, 1979.

[11] Mitchell, R.J., Ecosystem stability and resilience. Perspectives in Plant Ecology, Evolution and Systematics. 3(2): pp. 142-160, 2000.

[12] Jacquet, K. and R. Prodon, Résilience comparée des peuplements de Chêne vert et de Chêne liège après incendie. Rev. For. Fr. LIX: pp. 31-44, 2007.

[13] Loisel, R., Séries de végétation propres, en Provence, aux massifs des Maures et de l'Esterel (ripisilves exclues). Bull. Soc. bot. Fr. 118: pp. 203236, 1971.

[14] Molinier, R., Les études phytosociologiques en Provence cristalline. Bull. Mus. Hist. nat. Marseille. 33: pp. 7-45, 1973.

[15] Ladier, J. and C. Ripert, Les stations forestières de la Provence cristalline (Cap Sicié, îles d'Hyères, Maures, Tanneron), Typologie des stations forestières. Rapport du CEMAGREF: Aix-en-Provence. pp. $92+$ annexes, 1996.

[16] Trabaud, L., Wildland fire cycles and history in Central Southern France. International Conference on Forest Fire Research 2, Coimbra. pp. 545-556, 1994.

[17] Godron, M., et al., Code pour le relevé méthodique de la végétation et du milieu, ed. E.d. C.N.R.S. Paris. 292pp., 1983.

[18] Archaux, F. and L. Bergès, Optimising vegetation monitoring. A case study in A French lowland forest. Environ Monit Assess. 141: pp. 19-25, 2008.

[19] Kirby, K.J., et al., Seasonal and observer differences in vascular plant records from British woodlands. Journal of Ecology. 74: pp. 123-132, 1986.

[20] Braun-Blanquet, J., Les groupements végétaux de la France méditerranéenne: CNRS. 297pp., 1952.

[21] Brisse, H. and M. Kerguelen, Code informatisé de la flore de France. Vol. Tome 1: Bulletin de l'Association d'Informatique Appliquée à la Botanique, Marseille. 189pp., 1994.

[22] Gachet, S., E. Véla, and T. Tatoni, BASECO: a floristic and ecological database of Mediterranean French flora. Biodiversity and Conservation. 14: pp. 1023-1034, 2005.

[23] Hodgson, J.G., J.P. Grime, and R. Hunt, The Electronic Comparative Plant Ecology. London: Chapman and Hall. ISBN 0-412-63350-7, 1995.

[24] Lindacher, R., Phanart: Datenbank der Gefässpflanzen Mitteleuropas. Veröff. Geobotan. Inst. Zürich, 1995.

[25] Molinier, R. and P. Muller, La dissémination des espèces végétales. Rev. Gén. Bot. 50: pp. 178 p., 1938. 
[26] Pausas, J.G. and S. Paula, Plant functional traits database for EuroMediterranean ecosystems. Deliverable D-04-06, EUFIRELAB: pp. 29 p., 2006.

[27] Raunkiaer, C., The life-forms of plants and statistical plant geography. Clarendon Press, Oxford, 1934.

[28] Verlaque, R., F. Médail, and A. Aboucaya, Valeur prédictive des types biologiques pour la conservation de la flore méditerranéenne. C.R. Acad. Sci. Paris, Sciences de la vie / Life Sciences 324: pp. 1157-1165, 2001.

[29] Grime, J.P., Vegetation classification by reference to strategies. Nature. 250: pp. 26-31, 1974.

[30] Van der Pijl, L., Principles of dispersal in higher plants. Springer, Berlin, Heidelberg, New York, 1982.

[31] Legendre, P. and L. Legendre, Numerical Ecology. Developments in Environmental Modelling: Ed. Elsevier. 575-635pp., 1998.

[32] Ter Braak, C.J.F., Canonical Correspondence Analysis: a new eigenvector technique for multivariate direct gradient analysis. Ecology. 67: pp. 11671179, 1986.

[33] Sorensen, T., A method of establishing groups of equal amplitude in plant sociology based on similarity of species content and its applications to analysis of the vegetation on Danish commons. Biol. Skr. Udg. K. Dan. Vidensk. Selsk. . 5: pp. 1-34, 1948.

[34] Piélou, E.C., Species-Diversity and Pattern-Diversity in the Study of Ecological Succession. J. Theoretical Biology. 10: pp. 370-383, 1966.

[35] Shannon, C. and W. Weaver, The Mathematical Theory of Communication. University of Illinois Press, Urbana, 1949.

[36] Benzecri, J.P., L'Analyse des données: L'analyse des Correspondances. Vol. 2: 2e édition, Paris, Dunod. 619pp., 1976.

[37] Okland, R.H. and O. Eilerstein, Canonical correspondence analysis with variation partitioning: some comments and an application. J. Veg. Sci. 5: pp. 117-126, 1994.

[38] Akaike, H., A new look at statistical model identification. IEEE Transactions on Automatic Control AU. 19: pp. 716-722, 1974.

[39] Bergaglio, M., B. Talon, and F. Médail, Histoire et dynamique des forêts de l'ubac du massif des Maures au cours des derniers 8000 ans. Forêt méditerranéenne. t. XXVII, $\mathbf{n}^{\circ} \mathbf{1}, 2006$.

[40] Baeza, M.J., et al., Human disturbance and environmental factors as drivers of long-term post-fire regeneration patterns in Mediterranean forests. Journal of Vegetation Science. 18: pp. 243-252, 2007.

[41] Duguy, B. and R. Vallejo, Land-use and fire history effects on post-fire vegetation dynamics in eastern Spain. Journal of Vegetation Science. 19: pp. 97-108, 2008.

[42] Capitanio, R. and C. Carcaillet, Post-fire Mediterranean vegetation dynamics and diversity: a discussion of succession models. Forest Ecology and Management. 255: pp. 431-439, 2008. 
[43] Médail, F., P. Roche, and T. Tatoni, Functional groups in phytoecology: An application to the study of isolated plant communities in Mediterranean France. Acta Oecologica. 19(3): pp. 263-274, 1998.

[44] Rykiel, E.J., Towards a definition of ecological disturbance. Austral. J. Ecol. 10 pp. 361-366, 1985.

[45] Milchunas, D.G., O.E. Sala, and W.R. Lauenroth, A generalized model of the effects of grazing by large herbivores on grassland community structure. Am. Nat. 132: pp. 87-106, 1988.

[46] Allen, T.F.H. and T.B. Starr, Hierarchy. Perspectives for Ecological Complexity. The University of Chicago Press, Chicago and London: pp. 310, 1982.

[47] Véla, E., Biodiversité des milieux ouverts en région méditerranéenne. Le cas des pelouses sèches du Luberon (Provence calcaire). PhD thesis. University Aix-Marseille III. pp. 383, 2002. 